\title{
Numerical simulation of March 11, 2011 Honshu, Japan tsunami
}

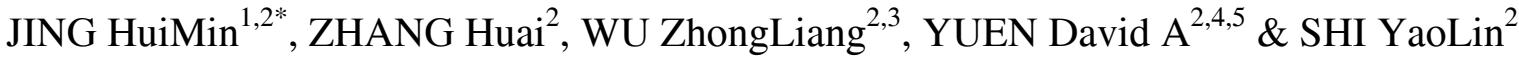 \\ ${ }^{1}$ College of Mechanical Engineering and Mechanics, Ningbo University, Ningbo 315211, China; \\ ${ }^{2}$ Key Laboratory of Computational Geodynamics, Chinese Academy of Sciences, Beijing 315211, China; \\ ${ }^{3}$ Institute of Geophysics, China Earthquake Administration, Beijing 100081, China; \\ ${ }^{4}$ Department of Geology and Geophysics, University of Minnesota, Twin Cities, MN 55455-0219, USA; \\ ${ }^{5}$ Minnesota Supercomputing Institute, University of Minnesota, Minneapolis, MN 55455, USA
}

Received February 14, 2012; accepted April 20, 2012; published online May 30, 2012

\begin{abstract}
In order to predict tsunami hazards through numerical simulation, by using the focal mechanisms as well as fault parameters of Japan's 2011 Tohoku Earthquake provided by National Geological Survey (referred to as USGS), we proposed a numerical model to simulate the Honshu, Japan tsunami. Numerical computing is conducted to investigate the security along the coast. We also analyzed the simulation results and distribution of tsunami disaster, trying to achieve a more reasonable tsunami warning program. Our numerical model is composed of simulation of surface deformation after the earthquake and the tsunami propagation process which is based on two dimensional shallow water equations. The simulation results show the characteristics of the tsunami propagation, and arrival times on recorder points are consistent with tsunami observation. This model can be applied to evaluate the security of the coastal area and obtain more accurate tsunami warning.
\end{abstract}

tsunami, numerical simulation, tsunami warning

Citation: Jing H M, Zhang H, Wu Z L, et al. Numerical simulation of March 11, 2011 Honshu, Japan tsunami. Chin Sci Bull, 2012, 57: 3617-3622, doi: $10.1007 / \mathrm{s} 11434-012-5229-5$

On March 11, 2011 at 05:46:23 Coordinated Universal Time there was an earthquake with Magnitude 9.0 near east coast of Honshu, Japan. The epicenter is about $70 \mathrm{~km}$ from the beach, which gave rise to more than $10 \mathrm{~m}$ high tsunami around the coastal area near Sendai and caused huge disaster. After the earthquake, approximately twenty countries around Pacific Ocean issued tsunami warning, which also caused great panic. Since 2004 Sumatra great earthquake tsunami, people pay more attention to the research of numerical simulation of tsunamis. The historical tsunami hazards in China are relatively low thus the research on tsunami started late, nevertheless much progress has been gained. For example, Yu et al. [1] of Marine Environmental Forecasting Center, State Oceanic Administration has proposed China Tsunami Travel Time model (CTTT), and applied this model to investigate the effect of 2010 Chile tsunami to

*Corresponding author (email: huiminjing@gmail.com)
China.

Tsunami is an oceanic gravity wave generated by submarine earthquakes or other geological processes such as volcanic eruptions or landslides [2]. Tsunami earthquakes take place most likely in trench regions with a large tectonic movement and young folded crustal belts. Most tsunamis are caused by shallow large earthquakes and hence are distributed along the subduction zones [3]. Recent tsunami events (e.g. Sumatra 2004, Java 2006, Solomon Islands 2007) demonstrate the need of providing accurate and timely tsunami warnings for all the ocean basins around the world. Improvements in the availability of sea-level observations and advances in numerical modeling techniques increase the potential for tsunami warnings based on numerical model forecasts. Numerical tsunami propagation and inundation models are well developed [4,5], but there presents a challenge for them in actual applications. In order to obtain deeper understanding of tsunamis and reduce their damage 
to human beings, we carried out the numerical simulation of this tsunami in Honshu, Japan, which can provide validation of our numerical model and further amendments. The eventual goal of our study is to make tsunami warnings timely and accurate.

\section{Numerical model of tsunamis}

\subsection{Numerical simulation of tsunami propagation processes}

Tsunami simulations have been conducted mostly in 2-D space on the basis of the long-wave approximation. Simulations based on the 2-D linear long-wave (LLW) equations are cost effective and widely used for tsunami propagation [6]. They are often employed to derive tsunami Green functions for the estimation of slip distribution along seismic faults or of an initial tsunami distribution [7,8]. They are also used in tsunami hazard assessments for happened and expected future large earthquakes $[9,10]$. For conventional tsunami simulations, the mass conservation equation that is also called the continuity equation of Shallow Water Equation is

$$
\frac{\partial h}{\partial t}+\frac{\partial}{\partial x}\left[\left(h-h_{B}\right) u\right]+\frac{\partial}{\partial y}\left[\left(h-h_{B}\right) v\right]=0,
$$

where $h(x, y, t)$ is the height of the ocean free surface, $h_{\mathrm{B}}(x$, $y$ ) is the height of the ocean's bathymetry, and $u$ and $v$ are the velocities in $x$ and $y$ directions, respectively.

As below is the momentum conservation equation

$$
\rho\left(\frac{D \vec{U}}{D t}+2 \vec{\Omega} \times \vec{U}\right)=-\rho \vec{g} \nabla h,
$$

where $\rho$ is density, $\vec{U}$ is velocity vector, $\vec{\Omega}$ is the angular velocity and $\vec{g}$ is acceleration of gravity.

Two-dimensional models are normally used for tsunami propagation simulations, as these models provide adequate solution while require relatively smaller memory and shorter computational time. This method is widely used in major international tsunami models, such as MOST [11], TUNAMI [12] and COMCOT [13]. TUNAMI procedures developed for UNESCO TIME project by F. Imamura from the Tohoku University apply staggered leapfrog scheme and finite difference method to solve equations. Because of being relatively simple and with open source to other researchers, TUNAMI model is widely used in tsunami simulation research. Yalciner once made a comparison between field survey and simulation results of TUNAMI-N2 model of the 2004 Indian Ocean tsunami, which roughly coincide with each other [14]. The main calculated part uses extensive validation TUNAMI-N1 program. Based on it, we improved the model's pre-process to achieve a convenient input method of real terrain data and expanded the amount of grids from tens of thousands to several million, while the grid size of the model is also decreased from thousands of meters to tens of meters. In addition, for far-field tsunamis, since the fault rupture process has relatively small effect, average dislocation model can satisfy the requirements. But the source of the Japanese tsunami is very close from the shore; the impact of rupture process needs to be considered. Generation mechanism of tsunami has been improved. The instantaneous and average dislocation model has been developed to fault rupture progress with time models. We also developed the post-processing to achieve a more direct visualization of results.

\subsection{Initial conditions of tsunamis-surface deformation calculation after the earthquake}

After the earthquake, several international research institutions rapidly published the preliminary results of the fault rupture process on website, including the United States National Earthquake Information Center (NEIC) [15], the United States Geological Survey (USGS) [16], Institute of Geophysics of the China Earthquake Administration (IGPCEA) [17], Institute of Geology and Geophysics of the Chinese Academy of Sciences (IGCAS) [18] and the Geospatial Information Authority of Japan (GSI) [19]. However, the slip distribution and fault rupture process issued by these institutions are varied from each other.

We set up several limited fault models according to these focal mechanisms, and compared their tsunami simulation results, and then we found that the results of average dislocation model are close to the actual observed data. Therefore, we used the average dislocation model, according to the focal mechanism issued by USGS http://earthquake.usgs. gov/earthquakes/eqinthenews/2011/usc0001xgp/neic_c0001 xgp_wmt.php, referring to seismic dislocations in the slip plane distribution obtained by Gavin Hayes (Finite Fault Model Preliminary Result of the Mar 11, $2011 M_{\mathrm{w}} 8.9$ Earthquake Offshore Honshu, Japan Gavin Hayes, USGS) and the aftershock distribution in the plate reduction belt (Subduction Zone Geometry Analysis Preliminary SZGC Results for $M$ 8.9 Earthquake near East Coast of Honshu, Japan, Gavin Hayes, NEIC), parameters of the fault being set as follows: epicenter, $38.321^{\circ} \mathrm{N}, 142.969^{\circ} \mathrm{E}$; fault length, $720 \mathrm{~km}$; fault width $200 \mathrm{~km}$; strike angle, 193 ${ }^{\circ}$; dip angle, $15^{\circ}$; slip angle $81^{\circ}$; average dislocation, $10 \mathrm{~m}$. Based on these parameters, we apply elastic half-space theory summarized by Okada [20] to calculate surface deformation of seabed after the earthquake as initial conditions of tsunami waves.

\section{Numerical simulation results and analysis}

In our simulation, the area near Japan has been chosen to investigate the characteristics of near-field tsunami. Figure 1 show the simulation results made by visualization software 

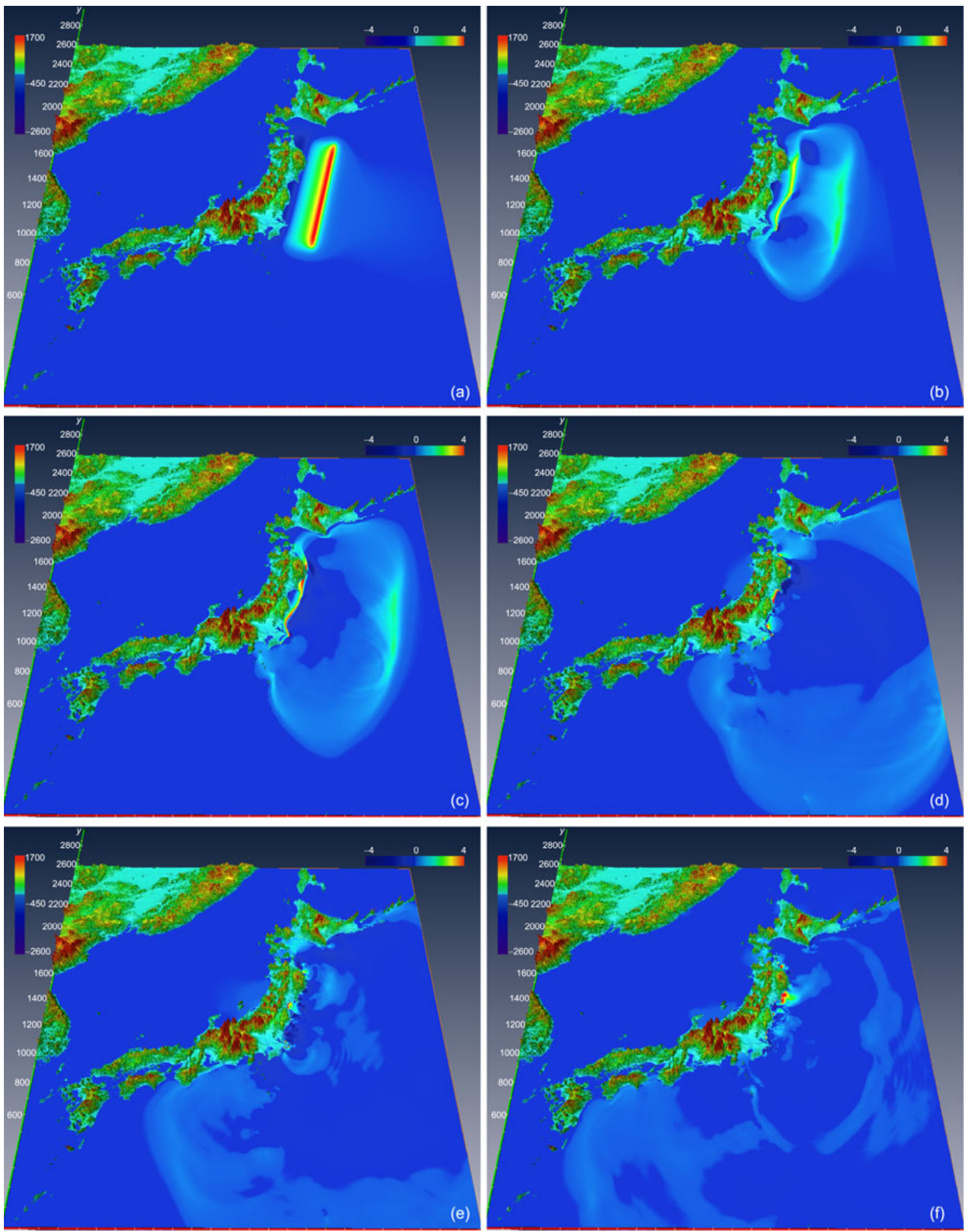

Figure 1 Simulation results of tsunami (unit of wave: m). (a) $T=0 \mathrm{~min}$; (b) $T=15 \mathrm{~min}$; (c) $T=30 \mathrm{~min}$; (d) $T=60 \mathrm{~min}$; (e) $T=90 \mathrm{~min}$; (f) $T=120 \mathrm{~min}$.

Amira [21].

Figure 1 shows the results of numerical simulation. Some of the features of tsunami propagation can be perceived: First, the strike and thrust dislocation of the fault determine the initial displacement, and the water above the fault is elevated and a little far from the source the water is dropped correspondingly, so along southeast coast of Hokkaido Is- land first-motion tsunami is negative, which is also illustrated by actual observation (Figure 2); second, Japan is on the hanging wall of the over thrust fault and because the epicenter is close to the shore and the range of fault rupture is large, there is a downward displacement of the land in the vicinity of Sendai caused by the earthquake, which is consistent with the GPS data; although the initial fluctuations 

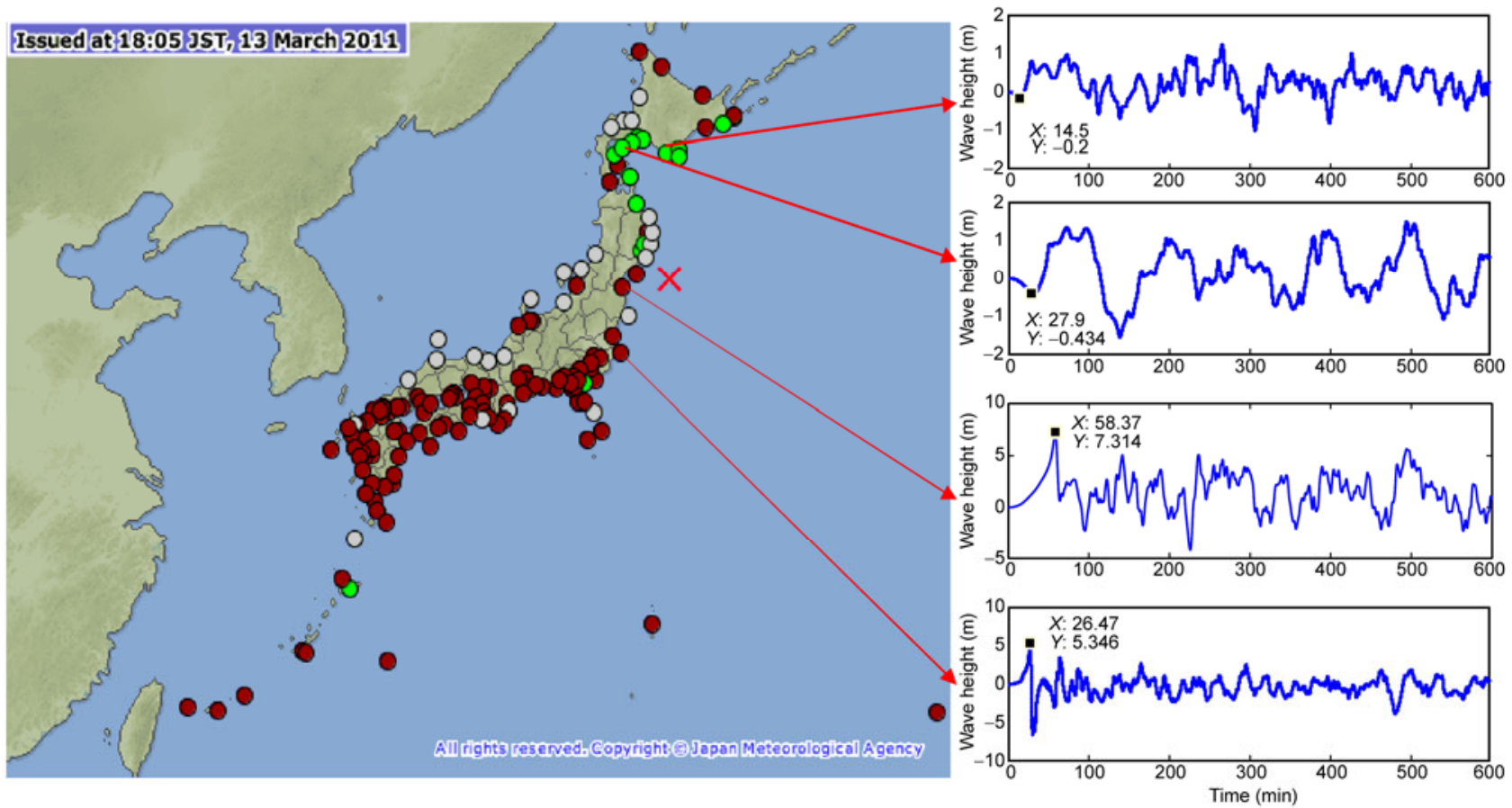

Figure 2 Observed rising/falling tides of first arrival tsunami and wave height vary with time get from numerical simulations.

also rapidly affected the eastern coast of Sendai, the relatively decline of the ground made the first arrival of tsunami as rising tides, which led to the first arrival tsunami in Sendai region different to other regions as shown in Figure 2; third, affected by fault strike, the tsunami split into two mainly waves propagate toward northwest and southeast, and due to the gradually shallower water in the direction of Japan's east coast, wave velocity decreases, while wave height increases rapidly and formed destructive tsunami near shore; at the same time, another tsunami wave moving toward the Pacific deep ocean with higher velocity, and due to energy dissipation in propagation process wave height is gradually reduced; fourth, during the wave propagation process, due to the barrier of land, island, or water depth changes, there are reflection, refraction and diffraction phenomena, leading to significant distinct wave height on different parts of the wave front in coastal regions; fifth, since the fault is roughly parallel to the east of Honshu Island coastline, and the initial tsunami is parallel to the fault, the positive barrier effect of Honshu island making tsunami near the Shikoku and Kyushu become diffraction wave, the maximum wave height is lower than that near Honshu and Hokkaido, and the specific wave height distribution will be discussed below.

In Figure 2, left side is observations of the first arrival tsunami recorded by Japan Meteorological Agency. Red plots indicate rising tides and green plots indicate falling tides. Right side is time series data of wave height varying with time on several points with positions corresponding to the stations in the left side figure. According to the recorders, first arrival tsunamis along south coast of Hokkaido
Island are falling tides while along east coast of Honshu Island are rising tides.

There are many tide stations and observations near Japan coast. These stations recorded the arrival time and wave height of tsunami. In order to do comparisons, we set recorder points at corresponding locations in numerical simulation. Figure 3 shows the maximum wave height comparison

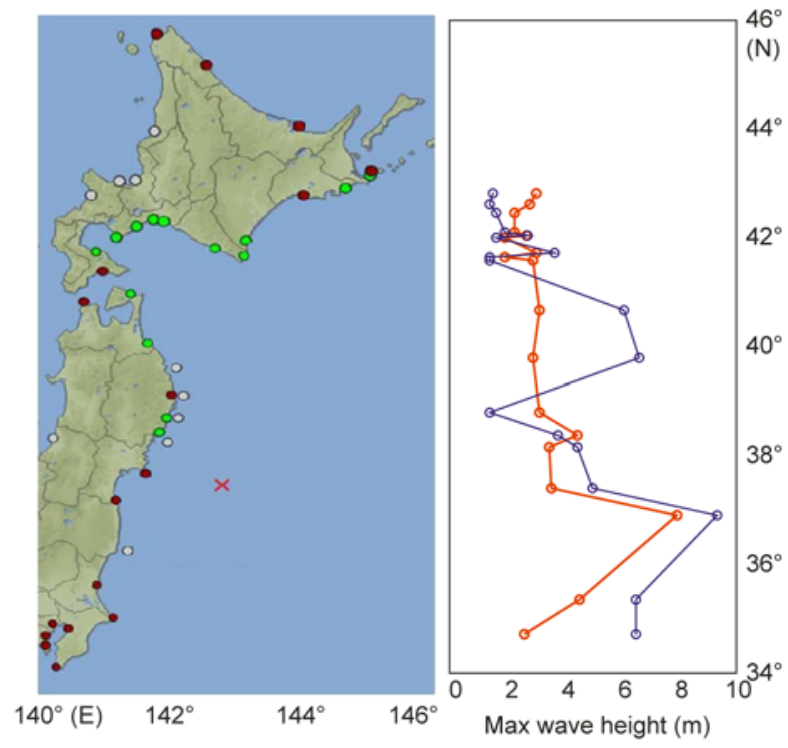

Figure 3 Comparison of maximum wave height between observed values (red line) on tide stations and recorded in the numerical experiment (blue line). The epicenter and the location of recording sites have been marked out. Observation data is provided by Japan Meteorological Agency: http:// www.jma.go.jp/jma/en/2011_Earthquake/2011_Earthquake_Tsunami.pdf. 
between observed by tide stations and recorded by recorder points in numerical simulation.

The distribution of wave heights along the coastline shown in Figure 3 indicates that simulation results are basically consistent with the actual records except for in the north part of Honshu Island. Using numerical simulation to obtained wave height distribution, we can predict the offshore tsunami disaster. In Figure 3, wave height recorder points have one-to-one correspondence with the observation stations. The maximum tsunami was in the gulf near eastern shore of Sendai. There were high tsunamis along Honshu Island and Hokkaido Island also, and these areas have more serious tsunami disaster. Furthermore, we compared wave height records at several gauges between the observed and the simulated result as shown in Figure 4.
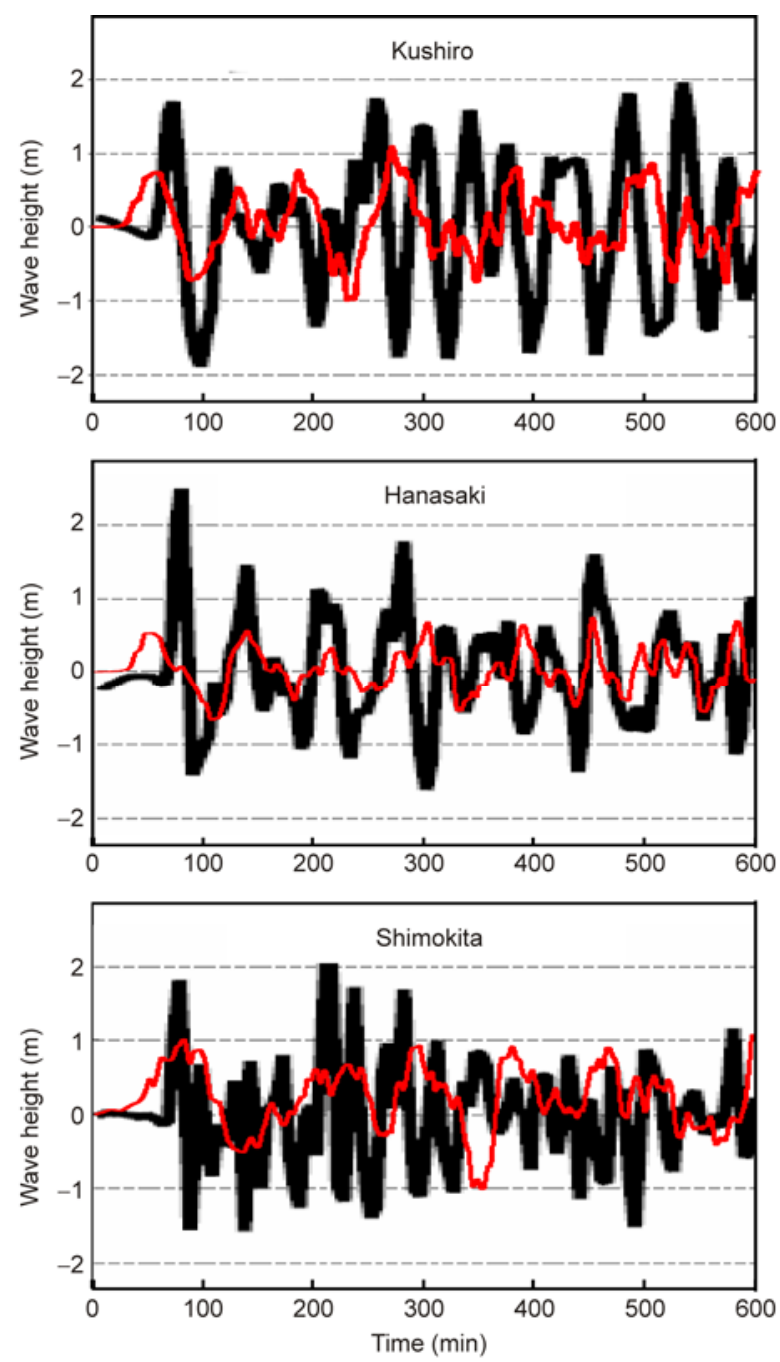

Figure 4 Comparisons of wave height records on gauges between observed and simulated results. The blank curves are the observed wave height records at three gauges along Honshu and Hokkaido coastal area, while the red curves are the records obtained from our numerical simulation. The point of time equal to zero indicates the time when the earthquake occurred.
It can be perceived that there is a degree of resemblance between the two kinds of records in wave forms changing. The reasons for the discrepancies are probable as following. First, most of the gauges are located alongshore where the waves affected by the shape of the shore intensely; thus observed wave records include the strong nonlinear progresses of run-up; while the run-up progresses have not been included in our present model. Second, since the bathymetry data using in the simulation is not precise enough, there should be deviation between the virtual and actual location of the gauges. Third, the interval of the observed wave record and the simulation's may be different.

\section{Discussion and conclusions}

Numerical models proposed in this study, using earthquakeinduced seabed deformation as the initial disturbance to simulate tsunami, can get results basically consistent with existing actual observation data, and wave height distribution can be used for coastal tsunami hazard prediction. The results of numerical simulation can reflect the characteristics of tsunami propagation. Using numerical simulation, we obtain reasonable explanation to why the first arrival tsunami in the vicinity of Sendai were rising tides. Numerical simulation results also reflect the wave front of the tsunami with different wave height due to the shallower water depth or the obstructions of islands.

However, there are deviations between numerical simulation and the observation, and some of the reasons may be as following: current numerical model does not include simulation of run-up process; bathymetry data in calculate area with less precision cannot reflect the terrain features accurately. Our preliminary numerical simulation results are helpful to understanding how the disaster is formed and to forecast the hazard distribution. At present, the focal mechanism, rupture process and the detailed wave height records on tide gauges have not been published yet in related fields around the world. Along with the disclosure of relevant information, we will do more collection, disposal and further simulations.

The island chain and the broad spread of the continental slope protect the coastline of Chinese mainland from the Pacific and Indian Ocean tsunamis. China is not a tsunami disaster-hit frequently country. However, the Eurasian plate downthrust under the Philippine plate in Manila Trench. There is a similar tectonic background with Chile, Sumatra, Sendai and other large-scale earthquake and tsunami regions. Liu et al. [22] once discussed the potential effects of $M_{\mathrm{w}} 8.0$ earthquake and tsunami in Manila trench to Guangdong, Fujian and Taiwan. Although it is just a small probability event, the unexpected occurrence of 2011 Honshu, Japan $M_{\mathrm{w}} 9.0$ earthquake and tsunami indicates that the potential tsunami hazard in Manila Trench should be re-evaluated. 
This work was supported by the Industry Fund Crustal Deep Exploration Project of the Ministry of Land and Resources (SinoProbe-07), the National Basic Research Program of China (2008CB425701), the National Hightech R\&D Program of China, High Performance Computing Software System for Earth System Model (2010AA012402), the National Natural Science Foundation of China (10872098) and K. C. Wong Magna Fund in Ningbo University.

1 Yu F J, Yuan Y, Zhao L D, et al. Evaluation of potential hazards from teletsunami in China: Tidal observations of a teletsunami generated by the Chile 8.8 $M_{\mathrm{w}}$ earthquake. Chin Sci Bull, 2011, 56, 3: 239-246

2 Satake K. 28 Tsunamis. In: Lee W H K, Kanamori H, Jennings P C, et al., eds. International Geophysics. Amsterdam: Academic Press, 2002. 437-451

3 Fukao Y. Tsunami earthquakes and subduction processes near deepsea trenches. J Geophys Res, 1979, 84: 2303-2314

4 Kervella Y, Dutykh D, Dias F. Comparison between three-dimensional linear and nonlinear tsunami generation models. Theor Comput Fluid Dyn, 2007, 21: 245-269

5 Saito T, Furumura T. Three-dimensional simulation of tsunami generation and propagation: Application to intraplate events. J Geophys Res, 2009, 114: B02307

6 Fujii Y, Satake K. Tsunami source of the 2004 Sumatra-Andaman earthquake inferred from tide gauge and satellite data. Bull Seismol Soc Am, 2007, 97: S192-S207

7 Satake K. Inversion of Tsunami waveforms for the estimation of heterogeneous fault motion of large submarine earthquakes: The 1968 Tokachi-oki and 1983 Japan Sea earthquakes. J Geophys Res, 1989, 94: 5627-5636

8 Baba T, Cummins P R, Hori T, et al. High precision slip distribution of the 1944 Tonankai earthquake inferred from tsunami waveforms: Possible slip on a splay fault. Tectonophysics, 2006, 426: 119-134

9 Geist E L, Titov V V, Arcas D, et al. Implications of the 26 December 2004 Sumatra-Andaman earthquake on tsunami forecast and assessment models for great subduction-zone earthquakes. Bull Seismol Soc Am, 2007, 97: S249-S270

10 Koh H L, Teh S Y, Liu P L-F, et al. Simulation of Andaman 2004 tsunami for assessing impact on Malaysia. J Asian Earth Sci, 2009, 36: 74-83

11 Titov V V, Synolakis C E. Extreme inundation flows during the Hokkaido-Nansei-Oki tsunami. Geophys Res Lett, 1997, 24: 1315

12 Imamura F, Shuto N, Goto C. Numerical simulations of the transoceanic propagation of tsunamis. In: Proceedings of the Sixth Congress Asian and Pacific Regional Division, IAHR. Kyoto, Japan. 1988. 265-272

13 Liu P L-F, Woo S B, Cho Y S. COMCOT User Manual Version 1.6, 2007

14 Yalciner A, Pelinovsky E, Talipova T, et al. Tsunamis in the Black Sea: Comparison of the historical, instrumental, and numerical data. $\mathrm{J}$ Geophys Res, 2004, 109: C12023

15 Hayes G. Subduction zone geometry analysis preliminary SZGC results for $M 8.9$ earthquake near east coast of honshu, Japan 2011. NEIC, 2011

16 Hayes G. Finite fault model preliminary result of the Mar 11, 2011 $M_{\mathrm{w}} 8.9$ earthquake offshore Honshu, Japan 2011. USGS, 2011

17 Chen Yuntai's Team. The 11 March 2011, $M_{\mathrm{w}} 9.0$ Tohoku, Japan Earthquake (in Chinese). China Earthquake Data Center, 2011

18 Wang W, Hao J, Yao Z. Preliminary result for rupture process of Mar. 11, 2011, $M_{\mathrm{w}} 8.9$ earthquake, near the East Coast of Honshu, Japan (in Chinese). IGCAS, 2011

19 Geospatial Information Authority of Japan. The 2011 off the Pacific coast of Tohoku Earthquake: Crustal Deformation and Fault Model. Geospatial Infor Auth Jpn, 2011

20 Okada Y. Surface deformation due to shear and tensile faults in a half-space. Bull Seismol Soc Am, 1985, 75: 1135-1154

21 Zhang H, Shi Y L, Yuen D A, et al. Modeling and visualization of tsunamis. Pure Appl Geophys, 2008, 165: 475-496

22 Liu Y, Santos A, Wang S M, et al. Tsunami hazards along Chinese coast from potential earthquakes in South China Sea. Phys Earth Planet Inter, 2007, 163: 233-244

Open Access This article is distributed under the terms of the Creative Commons Attribution License which permits any use, distribution, and reproduction in any medium, provided the original author(s) and source are credited. 